\title{
Polyether from a biobased Janus molecule as surfactant for carbon nanotubes
}

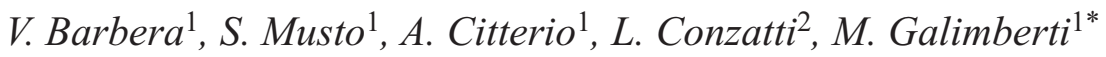 \\ ${ }^{1}$ Politecnico di Milano, Department of Chemistry, Materials and Chemical Engineering 'G. Natta', Via Mancinelli 7, \\ 20131 Milano, Italy \\ ${ }^{2}$ National Council of Research, Institute for the Study of Macromolecules, Via De Marini 6, 16149 Genova, Italy.
}

Received 20 November 2015; accepted in revised form 1 February 2016

\begin{abstract}
A new polyether (PE) was prepared from a biobased Janus molecule, 2-(2,5-dimethyl-1H-pyrrol-1-yl)-1,3propanediol (serinol pyrrole, SP). SP was synthesized with very high yield (about 96\%) and high atom efficiency (about $80 \%$ ) by reacting a biosourced molecule, such as serinol, with 2,5-hexanedione in the absence of solvent or catalyst. The reaction of SP with 1,6-dibromohexane led to PE oligomers, that were used as surfactants for multiwalled carbon nanotubes (MWCNT), in ecofriendly polar solvents such as acetone and ethyl acetate. The synergic interaction of aromatic rings and oxyalkylene sequences with the carbon allotrope led to dramatic improvement of surfactant efficiency: only $24 \%$ of SP based PE was extracted with ethyl acetate from the adduct with MWCNT, versus $98 \%$ of a typical pluronic surfactant. Suspensions of MWCNT-PE adducts in ethyl acetate were stable for months. High resolution transmission electron microscopy revealed a film of oligomers tightly adhered to MWCNT surface.
\end{abstract}

Keywords: nanomaterials, serinol, polyether, carbon nanotubes, surfactant

\section{Introduction}

Carbon Nanotubes (CNT) possess exceptional mechanical properties and the ability of conducting electrons without dissipating energy as heat. Research activity is performed on both single-walled $[1,2]$ and multi-walled [3, 4] CNT; one of main objectives is the preparation of even and stable CNT dispersions, both in liquid media and in polymer matrices, in view of many industrial applications. It is widely acknowledged [5-9] that the preparation of stable dispersions of CNT in liquid media has to overcome important obstacles: due to their large molar mass, not only CNT are insoluble in all known solvents but also they are greatly entangled. CNT are thus modified and partially coated with a dispersant phase that favors their compatibility with the liquid. Surfactants are the preferred molecules to prepare such a phase. Main goal of the research is to prepare stable CNT dispersions through simple processes that could preserve CNT integrity.

CNT are thus functionalized, through covalent chemical modification [5-8] or non covalent supramolecular interactions [8]. The latter ones are based on a variety of non bonded interactions such as $\pi-\pi$ stacking, cation- $\pi$ and charge transfer.

Polynuclear aromatic molecules are among the preferred compounds for non-covalent functionalization [8]. Recently, polymers with aromatic repeating units have been employed. Water dispersible nanofibrillar-polyaniline was wrapped on multiwalled carbon nanotubes (MWCNT) by an in situ polymerization [10]. Stable dispersions of MWCNT were obtained in organic solvents: in dimethylacetamide by modifying MWCNT with a poly(benzoxazole) (PBO) precursor [4] and obtaining by heating $\mathrm{CNT} / \mathrm{PBO}$ adduct film, in THF and toluene by using poly $(2,7-$

\footnotetext{
${ }^{*}$ Corresponding author, e-mail: maurizio.galimberti@polimi.it (C) BME-PT
} 
carbazole)s [5]. Single-walled carbon nanotubes (SWCNT) were dispersed in the same solvents thanks to poly(phenylacetylene)s with long alkyl tails on the side-chains [6].

Polyalkylene oxides are also acknowledged as efficient surfactants and research on these molecules is steadily performed [11-23]. Poly(ethylene oxide) and pluronic surfactants, i.e. triblock copolymers based on ethylene oxide and propylene oxide, are the preferred solubilizing polymers, particularly in view of biomedical applications. Since the first studies, it was reported that such surfactants, added at low percents, have a positive effect on the tube debundling [19]. Fluorescent labels on nanotubes were brought thanks to fluorescein-polyethylene glycol [11]. Polyoxyethylene sorbitan monooleate-suspended SWCNT were reported to favor the preparation of nanotubes suspensions for in vitro toxicological studies [12].

Objective of this work was to design a surfactant for CNT with much improved efficiency, thanks to the synergy between aromatic rings and oxyalkylene sequences. Such surfactant should be able to develop very efficient supramolecular interaction with CNT and to promote their dispersion in both hydrophobic and hydrophilic environments. To achieve such a goal, a poly(ether) based on the molecule shown in Figure 1 (2-(2,5-dimethyl-1H-pyrrol1-yl)-1,3-propanediol, serinol pyrrole, $\mathbf{S P}$ ) was prepared.

SP is a derivative of 2-amino-1,3-propanediol, known as serinol. It is directly obtainable from renewable sources [24] and can also be prepared from glycerol, a cheap, easily available raw material, non toxic and biodegradable. Glycerol comes from the biodiesel industry and a total amount of 1.2 million ton was available in 2010 [25-29]. Serinol is an interesting molecule for developing innovative synthetic strategies, thanks to the chemoselectivity of amino and hydroxyl groups. In recent papers, polymers from serinol have been reported: cyclic carbonates derivatives were converted into polymers through organocatalytic ring opening polymerization [30] and a compound obtained from the reaction of serinol with

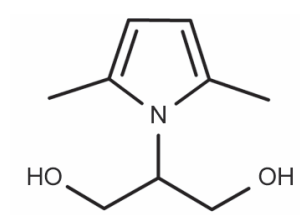

Figure 1. 2-(2,5-dimethyl-1H-pyrrol-1-yl)-1,3-propanediol (SP) succinimidyl ester of trimethyl-locked benzoquinone was used to prepare water soluble biodegradable polyester [31].

In this work, serinol chemoselectivity was exploited [32-34], preparing SP through the Paal-Knorr reaction [34, 35] of serinol (S) with 2,5-hexanedione (HD), performing the reaction in the absence of solvents and catalysts. SP has been defined as a Janus molecule [36], that means a molecule with two faces and, hence, a dual reactivity. The Roman god Janus, represented (for example in coins) as having two faces in one body, inspired the definition 'Janus' first to describe micro- and nanoparticles with at least two physically or chemically differing surfaces [37, 38 ] and then, more in general, molecules having two faces, a hydrophobic and a hydrophilic one, such as colloids [39] dendritic multiester [40], supermolecular liquid crystals [41], a binding protein for vitamin E [42], block copolymers with (meth)acrylic acid segments [43].

The Paal-Knorr reaction changes the $\mathrm{sp}^{3}$ hybridization of the nitrogen atom of the amino group and leads to the formation of $\mathrm{sp}^{2}$ atoms in the aromatic pyrrole ring. Pyrrole can give rise to $\pi-\pi$ stacking with aromatic compounds such as CNT and the hydroxyl groups allow the preparation of polymers such as polyethers by step-growth polymerization. First example of polymer obtained by step-growth polymerization, polyurethane, has been recently reported [33]. In this manuscript, polyethers from the reaction of $\mathbf{S P}$ with 1,6-dibromohexane are reported. They were characterized by means of infrared spectroscopy, ${ }^{1} \mathrm{H}$ and ${ }^{13} \mathrm{C}$ nuclear magnetic resonance (NMR), thermogravimetric analysis (TGA). MWCNT-PE adducts were prepared; their structure was studied by means of high transmission electron microscopy (HRTEM). MWCNT-PE suspensions were prepared in ecofriendly solvents, such as acetone and ethyl acetate, assessing their stability after several month storage, through UV-Vis spectroscopy.

\section{Experimental section}

\subsection{Materials}

Purified multi-walled nanotubes (NC7000 series) were purchased from NANOCYL ${ }^{\mathrm{TM}}$ Inc (www. nanocyl.com) and used as-supplied. Pluronic RPE 310 was poly(propylene glycol)-block-poly(ethylene glycol)-block-poly(propylene glycol) (PPG-PEGPPG, $\left.M_{\mathrm{n}}=3000\right)$ from BASF. 
Reagents and solvents commercially available were purchased and used without further purification: 2,5hexanedione (Merck - Schuchardt), 2-amino-1,3propanediol (kindly provided by Bracco), 1,6-dibromohexane (Sigma-Aldrich), potassium hydroxide (Carlo Erba Reagents), isopropyl alcohol (SigmaAldrich), acetone (Sigma-Aldrich), ethyl acetate (Sigma-Aldrich), DMSO-d6 (Sigma-Aldrich).

\subsection{Synthesis of 2-(2,5-dimethyl-1H-pyrrol-} 1-yl)-1,3-propanediol (SP)

A mixture of 2,5-hexanedione (41.42 g; $0.36 \mathrm{~mol})$ and serinol (30.02 g; $0.36 \mathrm{~mol}$ ) was poured into a $100 \mathrm{~mL}$ round bottomed flask equipped with magnetic stirrer. The mixture was then stirred, at room temperature, for $6 \mathrm{~h}$. Without any purification the mixture reaction was warmed up to $180^{\circ} \mathrm{C}$ for $8 \mathrm{~h}$. The pyrrole derivative was isolated by distillation under reduced pressure at $130^{\circ} \mathrm{C}$ and $0.1 \mathrm{mbar}$. Yellow oil was obtained with $96 \%$ yield. ${ }^{1} \mathrm{H}$ NMR (400 MHz, DMSO- $d 6, \delta$ in ppm): $2.16\left(\mathrm{~s}, 6 \mathrm{H},-\mathrm{CH}_{3}\right.$ at $\mathrm{C}-2,5$ of pyrrole moiety); $3.63\left(\mathrm{~m}, 2 \mathrm{H}, \mathrm{CH}_{2} \mathrm{OH}\right)$; $3.76\left(\mathrm{~m}, 2 \mathrm{H}, \mathrm{CH}_{2} \mathrm{OH}\right.$ ); 4.10 (quintet, $1 \mathrm{H}$, at $\mathrm{C}-3$ of diol); 4.73 (t, 2H, $\left.\mathrm{CH}_{2} \mathrm{OH}\right) ; 5.55$ (s, 2H, C-3,4 of pyrrole moiety).

\subsection{Polymerization reactions}

\section{Run 1 of Table 1}

In a $50 \mathrm{~mL}$ round bottom flask equipped with a magnetic stirrer were added $\mathbf{S P}(0.200 \mathrm{~g}, 1.18 \mathrm{mmol})$ and potassium hydroxide $(0.200 \mathrm{~g}, 2.36 \mathrm{mmol})$. The resulting mixture was sonicated for 30 minutes in a $2 \mathrm{~L}$ sonication bath. After this period, a solution of 1,6dibromohexane $(0.218 \mathrm{~mL})$ in $3 \mathrm{~mL}$ of isopropyl alcohol was added and stirred at $90^{\circ} \mathrm{C}$ for 30 minutes. A sample was taken for determination of the conversion by ${ }^{1} \mathrm{H}$ NMR spectroscopy. After cooling at room temperature, water $(10 \mathrm{~mL})$ was first added and isopropyl alcohol was removed. To the mixture was then added ethyl acetate and extracted $(3 \times 25 \mathrm{~mL})$. The organic phase was dried on $\mathrm{Na}_{2} \mathrm{SO}_{4}$ and the solvent was removed. The polymer was isolated by dissolution in $\mathrm{CH}_{2} \mathrm{Cl}_{2}(2 \mathrm{~mL})$, precipitation from excess diethyl ether $(50 \mathrm{~mL})$, filtration, and drying in vacuo.

\section{Run 2 of Table 1}

In a $25 \mathrm{~mL}$ round bottom flask equipped with a magnetic stirrer were added in sequence SP $(0.100 \mathrm{~g}$,
$0.59 \mathrm{mmol})$ and potassium hydroxide $(0.100 \mathrm{~g}$, $1.18 \mathrm{mmol})$. After stirring for 30 minutes, 1,6-dibromohexane $(0.109 \mathrm{~mL})$ was added to the mixture and sonicated for 30 minutes in a $2 \mathrm{~L}$ sonication bath. After this period, the mixture was irradiated at $130^{\circ} \mathrm{C}$ for 30 minutes by microwave. A sample was taken for determination of the conversion by ${ }^{1} \mathrm{H}$ NMR spectroscopy. After cooling at room temperature, water $(10 \mathrm{~mL})$ was first added and was extracted using ethyl acetate $(3 \times 10 \mathrm{~mL})$. The organic phase was dried on $\mathrm{Na}_{2} \mathrm{SO}_{4}$ and the solvent was removed. The polymer was isolated by dissolution in $\mathrm{CH}_{2} \mathrm{Cl}_{2}(2 \mathrm{~mL})$, precipitation from excess hexane $(50 \mathrm{~mL})$, filtration, and drying in vacuo.

\section{Run 3 of Table 1}

In a $25 \mathrm{~mL}$ round bottom flask equipped with a magnetic stirrer were added in sequence SP $(0.100 \mathrm{~g}$, $0.59 \mathrm{mmol})$ and potassium hydroxide $(0.100 \mathrm{~g}$, $1.18 \mathrm{mmol}$ ). After stirring for 30 minutes, 1,6-dibromohexane $(0.109 \mathrm{~mL})$ was added to the mixture. The resulting mixture was sonicated for 30 minutes in a $2 \mathrm{~L}$ sonication bath and after was stirred at $130^{\circ} \mathrm{C}$ for 60 minutes. A sample was taken for determination of the conversion by ${ }^{1} \mathrm{H}$ NMR spectroscopy. After cooling at room temperature, water $(10 \mathrm{~mL})$ was first added and was extracted using ethyl acetate $(3 \times 10 \mathrm{~mL})$. The organic phase was dried on $\mathrm{Na}_{2} \mathrm{SO}_{4}$ and the solvent removed. The polymer was isolated by dissolution in $\mathrm{CH}_{2} \mathrm{Cl}_{2}(2 \mathrm{~mL})$, precipitation from excess hexane $(50 \mathrm{~mL})$, filtration, and drying in vacuo.

\subsection{Preparation of MWCNT adducts \\ With SP based PE}

Dispersion of CNT in acetone was prepared $(1 \mathrm{mg} / \mathrm{mL})$ sonicating for 30 minutes in a $2 \mathrm{~L}$ sonication bath. A PE solution in acetone was added $(1 \mathrm{mg} / \mathrm{mL})$ to the previously obtained instable suspension. The mixture was sonicated for other $30 \mathrm{~min}-$ utes. The powder of MWCNT/SP adduct was isolated by evaporating the solvent.

\section{With Pluronic 3110}

The same procedure was followed except that $5 \mathrm{mg}$ of Pluronic 3110 were used.

The resulting suspension was then centrifuged at $5000 \mathrm{rpm}$ for 5 minutes to test its stability. 


\subsection{Extraction with ethyl acetate of MWCNT adducts}

$100 \mathrm{mg}$ of MWCNT adduct in the powder form, either with SP based PE or with Pluronic 3110, was placed in a round bottomed flask $(50 \mathrm{~mL})$ equipped with a magnetic stirrer and ethyl acetate $(25 \mathrm{~mL})$ was added. The ensuing suspension, after being stirred overnight at room temperature, was centrifuged at $9000 \mathrm{rpm}$ for 30 minutes and dried under vacuum. The so obtained black powder was analyzed by TGA.

\subsection{Characterization}

Nuclear magnetic resonance analysis

One-dimensional ${ }^{1} \mathrm{H}$ - and ${ }^{13} \mathrm{C}$ NMR spectra were measured at 400 and $100 \mathrm{MHz}$, respectively, using a Bruker AV 400 equipped with a $5 \mathrm{~mm}$ multinuclear probe with reverse detection (Bruker, Rheinstetten, Germany). The solvent was deuterated Chloroform and the temperature was $27^{\circ} \mathrm{C}$. The experimental time for ${ }^{13} \mathrm{C}$ NMR spectra was typically $12 \mathrm{~h}$ (corresponding to more than 10000 scans). Data were processed using TOPSPIN 1.1 or MestReNova. Centrifugations were performed using an ALC - Centrifugette 4206.

\section{Thermal gravimetric analysis}

TGA analysis under $\mathrm{N}_{2}$ were performed with a Mettler TGA SDTA/851 instrument according to the standard method ISO 9924-1. Samples (10 mg) were heated from 30 to $300^{\circ} \mathrm{C}$ at $10^{\circ} \mathrm{C} / \mathrm{min}$, kept at $300^{\circ} \mathrm{C}$ for $10 \mathrm{~min}$, and then heated up to $550^{\circ} \mathrm{C}$ at $20^{\circ} \mathrm{C} / \mathrm{min}$. After being maintained at $550^{\circ} \mathrm{C}$ for $15 \mathrm{~min}$, they were further heated up to $650^{\circ} \mathrm{C}$ with an heating rate of $30^{\circ} \mathrm{C} / \mathrm{min}$ and kept at $650^{\circ} \mathrm{C}$ for $20 \mathrm{~min}$ under flowing air $(60 \mathrm{~mL} / \mathrm{min})$.

\section{FT-IR spectroscopy attenuated total reflectance (ATR)}

IR spectra were recorded between 450 and $4000 \mathrm{~cm}^{-1}$ by using a Perkin Elmer FT-IR spectrum one equipped with Universal ATR Sampling Accessory with diamond crystal.

\section{High resolution transmission electron microscopy}

HRTEM analysis of the MWCNT adduct with the PE sample containing the pyrrole ring was performed with a Zeiss Libra ${ }^{\circledR} 200 \mathrm{FE}$ microscope (Carl Zeiss AG, Oberkochen, Germany) operating at $200 \mathrm{kV}$ and equipped with an in-column OMEGA filter for energy selective imaging and diffraction. Few drops of acetone diluted suspension of the sample were deposited on a holey carbon film supported on a standard $\mathrm{Cu}$ grid and air-dried for several hours before analysis.

\section{Wide-angle X-ray diffraction}

WAXD patterns were obtained in reflection, with an automatic Bruker D8 Advance diffractometer, with nickel filtered $\mathrm{Cu}-\mathrm{K} \alpha$ radiation. They were recorded in 10 and $80^{\circ}$ as the $2 \Theta$ range, being $2 \Theta$ the peak diffraction angle. Distance between crystallographic planes was calculated from the Bragg law. The $D_{\mathrm{hkl}}$ correlation length, in the direction perpendicular to the $h k l$ crystal graphitic planes, was determined applying the Scherrer equation (Equation (1)):

$$
D_{\mathrm{hkl}}=\frac{K \lambda}{\beta_{\mathrm{hkl}} \cos \Theta_{\mathrm{hkl}}}
$$

where $K$ is the Scherrer constant, $\lambda$ is the wavelength of the irradiating beam $(1.5419 \AA, \mathrm{Cu}-\mathrm{K} \alpha), \beta_{\mathrm{hkl}}$ is the width at half height, and $\Theta_{\mathrm{hkl}}$ is the diffraction angle. The instrumental broadening, $b$, was determined by obtaining a WAXD pattern of a standard silicon powder 325 mesh (99\%), under the same experimental conditions. The width at half height, $\beta_{\mathrm{hkl}}=$ $\left(B_{\mathrm{hkl}}-b\right)$ was corrected, for each observed reflection with $\beta_{\mathrm{hkl}}<1^{\circ}$, by subtracting the instrumental broadening of the closest silicon reflection from the experimental width at half height, $B_{\mathrm{hkl}}$.

\section{UV-Vis spectroscopy}

UV-Vis absorption measurements were made using a Hawlett Packard 8452A Diode Array Spectrophotometer.

\section{Results and discussion}

Synthesis of 2-(2,5-dimethyl-1H-pyrrol-1-yl)-1,3propanediol (SP)

The synthesis of SP, summarized in Figure 2, is described in detail in the experimental part and has been discussed elsewhere [32, 33].

In brief, serinol (S) was first reacted with 2,5-hexanedione (HD), adopting the Paal-Knorr reaction, obtaining the tricyclic compound 4a,6a-dimethyl-hexahydro-1,4-dioxa- $6 b$-azacyclopenta[ $c d]$ pentalene

(HHP), that was then converted into SP. The reaction is characterized by high atom economy (82\%) and water is the only co-product of the first step. In all the SP syntheses carried out for the present work, 
<smiles>NC(CO)CO</smiles>

$S$<smiles>CC(=O)CCC(C)=O</smiles>

$H D$

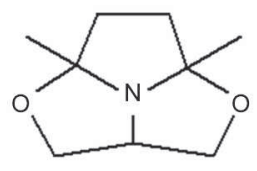

HHP

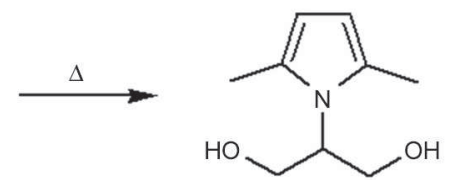

SP

Figure 2. Synthesis of SP from serinol (S) and 2,5-hexanedione

(HD)

high yield, about $96 \%$, was easily reproduced. Atom efficiency of about $78 \%$ was thus obtained.

Poly(ether)s from $\boldsymbol{S P}$ and 1,6-dibromohexane (DBH) Polyether synthesis was carried out by using equimolar amounts of SP and DBH, as it is shown in Figure 3. $\mathrm{KOH}$ was used as the base to promote the polymerization: alcolates formed from the $\mathrm{OH}$ groups of SP performed the nucleophilic attack on the $\mathrm{C}-\mathrm{Br}$ bond of $\mathbf{D B H}$, as in a classical Williamson reaction $[44,45]$. Polymerizations here discussed were carried out at different temperatures $\left(90\right.$ and $\left.130^{\circ} \mathrm{C}\right)$ and for different times (30 and 60 minutes), either in the absence or in the presence of a solvent such as isopropanol.

Table 1 shows polymerization conditions and data of number average molar mass $\left(\bar{M}_{\mathrm{n}}\right)$ obtained from NMR analysis.

Low molar masses were obtained in the performed tests. Test carried out in $i-\mathrm{PrOH}$ at $90^{\circ} \mathrm{C}$ for $30 \mathrm{~min}-$ utes as the solvent gave $\bar{M}_{\mathrm{n}}$ of about $1800 \mathrm{~g} \cdot \mathrm{mol}^{-1}$. Lower molar mass was obtained performing the

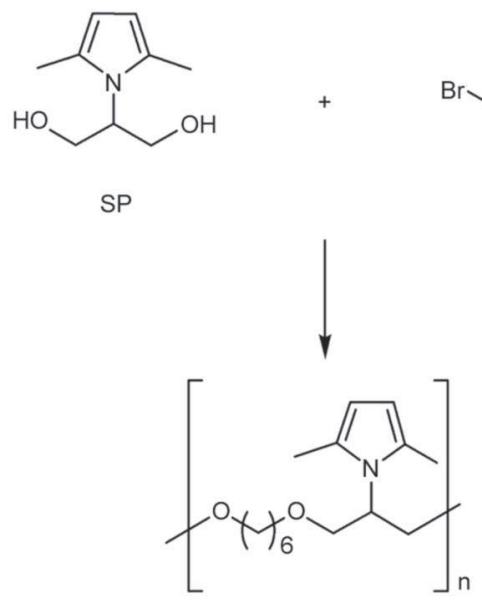

Figure 3. Synthesis of PE from SP and DBH reaction for the same time but in the absence of solvent and at higher temperature $\left(130^{\circ} \mathrm{C}\right)$. Larger value of $\bar{M}_{\mathrm{n}}$, about $2.600 \mathrm{~g} \cdot \mathrm{mol}^{-1}$, was achieved at $130^{\circ} \mathrm{C}$, in the absence of a solvent and for a longer polymerization time. Research was not performed in order to enhance the molar mass of poly(ethers), as they were conceived as surfactants for CNT and the low molar mass was seen as beneficial. Research for enhancing the molar mass should carefully control the chemical purity of the comonomers and hence the stoichiometry of the reaction. Moreover, the large steric hindrance of SP as the diol, as well as the $\pi-\pi$ interactions established by the pyrrole ring, should be investigated.

The nature of functional groups present in the oligomers obtained from runs $1-3$ of Table 1 was investi-

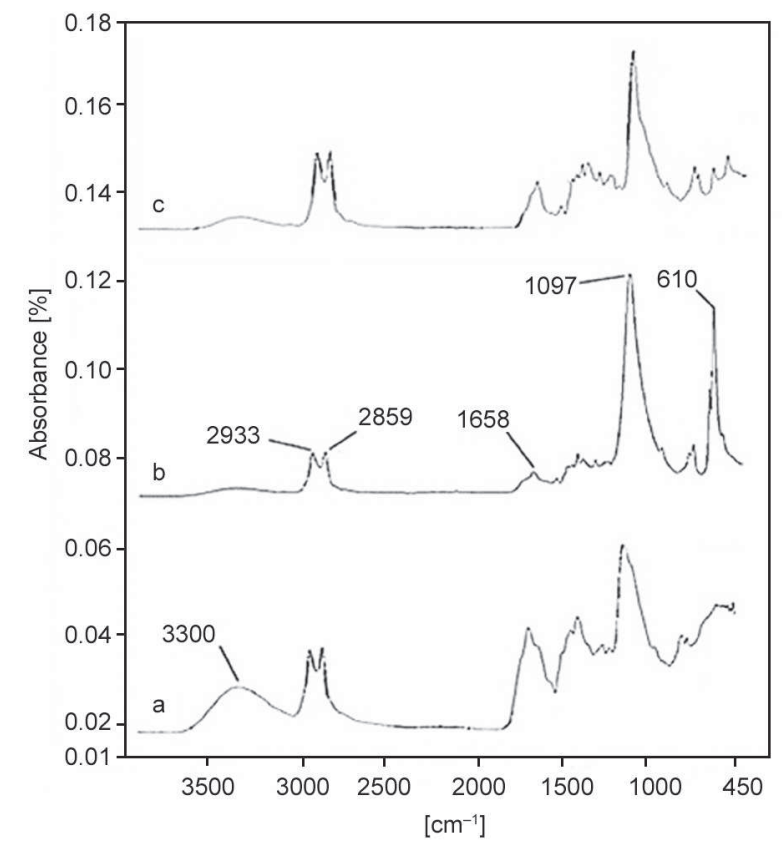

Figure 4. FT-ATR spectra $\left[\mathrm{cm}^{-1}\right]$ of sample from run 1 (a), run 2 (b) and run 3 (c) of Table 1.

Table 1. PE from SP and DBH: polymerization conditions and molar masses.

\begin{tabular}{|c|c|c|c|c|c|c|c|}
\hline Run & $\begin{array}{c}\text { DBH } \\
{[\mathbf{m m o l}]}\end{array}$ & $\begin{array}{c}\text { SP } \\
{[\mathbf{m m o l}]}\end{array}$ & $\begin{array}{c}\text { KOH } \\
{[\mathbf{m m o l}]}\end{array}$ & Solvent & $\begin{array}{c}\boldsymbol{T} \\
{\left[{ }^{\circ} \mathbf{C}\right]}\end{array}$ & $\begin{array}{c}\boldsymbol{t} \\
{[\mathbf{m i n}]}\end{array}$ & $\begin{array}{c}\overline{\boldsymbol{M}}_{\mathbf{n}}^{\mathbf{a}} \\
{\left[\mathbf{g} \cdot \mathbf{m o l}^{-\mathbf{1}} \mathbf{]}\right.}\end{array}$ \\
\hline 1 & 1.18 & 1.18 & 2.36 & $\mathrm{iPr}-\mathrm{OH}^{\mathrm{b}}$ & 90 & 30 & 1.75 \\
\hline 2 & 0.59 & 0.59 & 1.18 & - & 130 & 30 & 1.08 \\
\hline 3 & 0.59 & 0.59 & 1.18 & - & 130 & 60 & 2.60 \\
\hline
\end{tabular}

${ }^{\mathrm{a}}$ number average molar mass from ${ }^{1} \mathrm{H}$ NMR analysis, ${ }^{\mathrm{b}}$ isopropyl alcohol. 
gated through FT-ATR spectroscopy. Figure 4 shows the FT-ATR spectra of the reaction products from run 1 (Figure 4 curve a), run 2 (Figure 4 curve b) and run 3 (Figure 4 curve c) of Table 1.

In all the spectra shown in Figure 4, the $-\mathrm{C}-\mathrm{O}-\mathrm{C}-$ ether group is revealed by the characteristic strong band at $1097 \mathrm{~cm}^{-1}$. Peaks due to the pyrrole ring are at 1656,1461 and $1418 \mathrm{~cm}^{-1}$. Stretching of $\mathrm{CH}_{2}$ group is revealed by peaks at 2933 and $2859 \mathrm{~cm}^{-1}$.

FT-ATR traces of PE obtained from run 1 and run 2 of Table 1 shown bands of the bromine end group at $610 \mathrm{~cm}^{-1}$ (Figure 4 curve a) and of hydroxyl end group (Figure 4 curve b) at $3300 \mathrm{~cm}^{-1}$ respectively. The relative intensities of the bands due to the methylene sequence and to the ether linkage, at $2933 \mathrm{~cm}^{-1}$ and at $1097 \mathrm{~cm}^{-1}$ respectively, can be estimated in the three spectra: values are 1:2, 1:3 and 1:7 for PE from run 3,1 and 2. Such values appear to be in line with the increasing molar mass.

Oligomers microstructure was studied by means of ${ }^{1} \mathrm{H}$ and ${ }^{13} \mathrm{C}$ NMR analysis. Figure 5 shows the ${ }^{1} \mathrm{H}$ NMR spectra of the reaction products of run 1 (Figure 5 curve a) and run 3 (Figure 5 curve b) of Table 1.
In both ${ }^{1} \mathrm{H}$ NMR spectra of Figure 5, chemical shifts are consistent with the proposed polymer structure. Hydrogen in 3 and 4 position of the pyrrole in the repeating units, should give one signal. In this case, the two singlets at 5.73 and at $5.71 \mathrm{ppm}$ are probably due to the hydrogen atoms of the pyrrole in the repeating units and in the chain ends. The signal at $4.41 \mathrm{ppm}$ can be attributed to the $-\mathrm{NCH}$ hydrogen near the heterocyclic nitrogen. Peaks at 3.79 and at $3.71 \mathrm{ppm}$ are due to the resonances from diastereotopic hydrogens of ether linkage $\left(\mathrm{CH}_{2}-\mathrm{O}-\mathrm{C}\right)$.

Peaks at 3.99 and 3.90 ppm in Figure 5 curve a indicate the presence of $\mathrm{CH}_{2} \mathrm{OH}$ terminals, whereas are absent in the spectrum in Figure 5 curve $b$ of the PE, from run 3, with higher molar mass. Both spectra also show at $2.17 \mathrm{ppm}$ the characteristic signals of the methyl group bound in $\mathrm{C}-2$ of the pyrrolic ring.

Thermal stability of SP based oligomers was assessed by means of thermal gravimetric analysis. SP achieves its boiling point at about $230^{\circ} \mathrm{C}$. TGA curve shows decomposition profile made by three main steps. The decomposition of pyrrole moiety, oxygen-containing and alkenylic groups occurs in temperature range<smiles>COC[C@@H](COCCCCCC(C)(C)C)n1c(C)ccc1C</smiles>

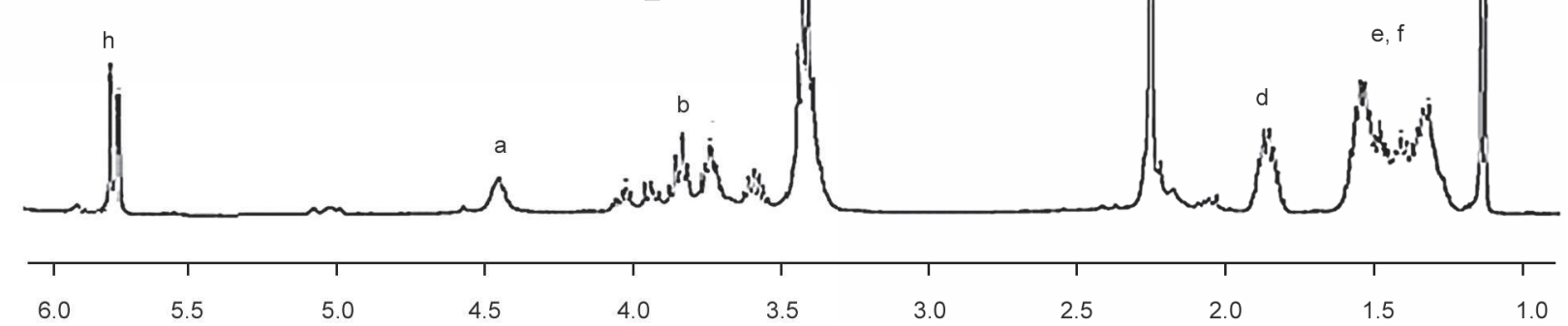

a)

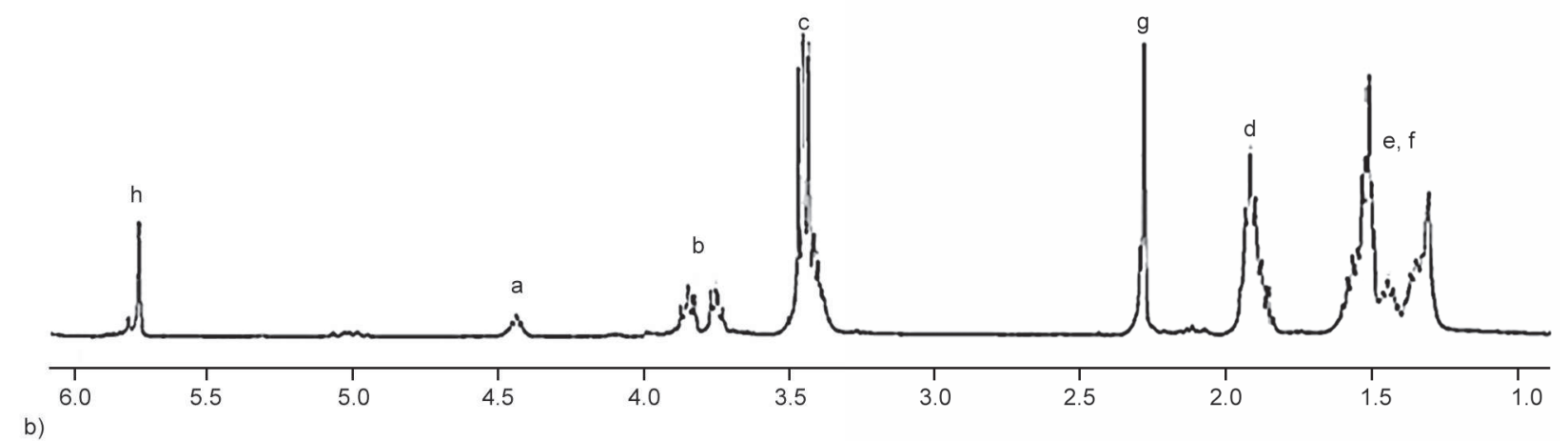

Figure 5. $400 \mathrm{MHz}{ }^{1} \mathrm{H}$ NMR spectra in $\mathrm{CDCl}_{3}$ of sample from run 1 (a) and from run 3 (b) of Table 1 
from 150 to $700^{\circ} \mathrm{C}$ and the combustion with oxygen (see experimental part) at $T>700^{\circ} \mathrm{C}$. Mass loss due to water removal, that could be expected at $T<$ $150^{\circ} \mathrm{C}$ in consideration of the hydroxyl end groups, is not be detected.

\section{MWCNT-PE adducts}

MWCNT-PE adducts were prepared as described in the experimental part. Briefly, a suspension of CNT in acetone $(1 \mathrm{mg} / \mathrm{mL})$ was sonicated with a $2 \mathrm{~L}$ bath sonicator for 30 minutes, obtaining an unstable suspension. A solution in $5 \mathrm{~mL}$ of acetone, of $10 \mathrm{mg}$ of PE sample from run 3 of Table 1, was then added to $5 \mathrm{~mL}$ of CNT suspension (10 mg), immediately after its sonication. Further sonication was carried out for 30 minutes. The chemical composition and the structure of CNT coated with PE oligomer (sample from run 3 of Table 1) were then investigated by means of TGA, XRD analysis and HRTEM. Sample for the analysis was isolated by carefully taking the upper part of the supernatant suspension obtained after centrifugation, evaporating then the solvent.

In Figure 6 are reported the thermographs of SP, polyether from run 3 of Table 1 and the MWCNT-PE adduct based on such polymer after extraction with ethyl acetate. As reported in Table 2, PE thermal degradation profile shows three main losses due to

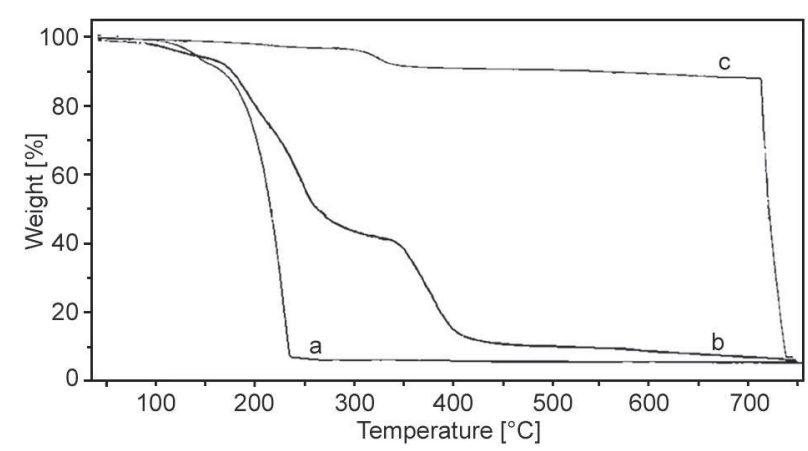

Figure 6. TGA curves taken under $\mathrm{N}_{2}$ of: $\mathbf{S P}(\mathrm{a}), \mathrm{PE}(\mathrm{b})$, MWCNT-PE adduct after extraction with ethyl acetate (c), with PE sample from run 3 of Table 1

Table 2. Mass loss for SP and SP based oligomers from Table 1 obtained by TGA analysis

\begin{tabular}{|l|c|c|c|}
\hline \multirow{3}{*}{ Sample } & \multicolumn{3}{|c|}{$\begin{array}{c}\text { Mass loss } \\
{[\%]}\end{array}$} \\
\cline { 2 - 4 } & $\boldsymbol{T}<\mathbf{2 5 0}^{\circ} \mathbf{C}$ & $\mathbf{2 5 0}^{\circ} \mathbf{C}<\boldsymbol{T}<\mathbf{5 0 0}^{\circ} \mathbf{C}$ & ${\boldsymbol{T}>\mathbf{5 0 0}^{\circ} \mathbf{C}}^{\circ}$ \\
\hline SP & 100 & 0 & 0 \\
\hline PE-1 $^{\text {a }}$ & 40 & 37 & 23 \\
\hline PE-2 $^{\text {a }}$ & 48 & 31 & 21 \\
\hline PE- $^{\text {a }}$ & 52 & 28 & 20 \\
\hline
\end{tabular}

apolyethers from the runs of Table 1 the degradation of the ether-pyrrole moieties and methylene sequences (see Figure 6 curve b). In the MWCNT-PE adduct trace degradation of the adsorbed polymer occurs at a temperature much higher than the one observed in the PE curve. From TGA, the content of PE after extraction with ethyl acetate was calculated to be about $10 \%$.

Figure 7 shows the XRD patterns, in the $10-80^{\circ}$ as $2 \Theta$ range, of pristine MWCNT (Figure 7 curve a) and of the MWCNT-PE adduct (Figure 7 curve b). XRD pattern of a graphitic crystalline carbon allotrope with many stacked graphene layers, shows, as the most intense peaks, some (00l) and ( $h k l)$ reflections, that remain visible also when the number of stacked layers is reduced to few tenths [46]: 002 and 004, at 26.2 and $54.3^{\circ}$ as $2 \Theta$ value, with a $d_{002}$ interlayer distance of $0.34 \mathrm{~nm}, 100$ and 110 reflections at 42.8 and $77.5^{\circ}$ as $2 \Theta$ value. The pattern in Figure 7 of MWCNT that has a low number of wrapped layers shows only the two most intense reflections: 002 at $25.3^{\circ}$ and 100 at $42.8^{\circ}$. The dimension of crystallites in direction orthogonal to CNT layers can be estimated, by calculating the correlation length $D_{001}$, through the Scherrer equation (Equation (1)). A value of about $2.7 \mathrm{~nm}$ was obtained for pristine tubes. Taking into account the distance between two successive layers in CNT graphitic crystal, 8 was estimated as the number of CNT layers. In the pattern of MWCMTPE adduct the 002 and the 110 reflections are clearly visible. The number of wrapped layers was estimated to be about 8 .

Morphological analysis of MWCNT and MWCNTPE adducts was performed through HRTEM analysis at different magnifications. The micrograph in Fig-

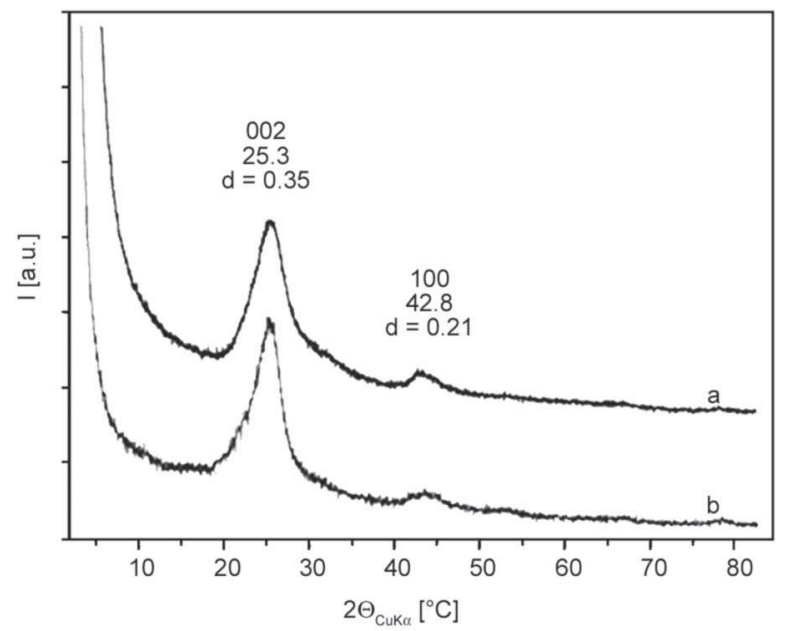

Figure 7. XRD diffraction spectra of: pristine MWCNT (a) and MWCNT-PE adducts (b) 


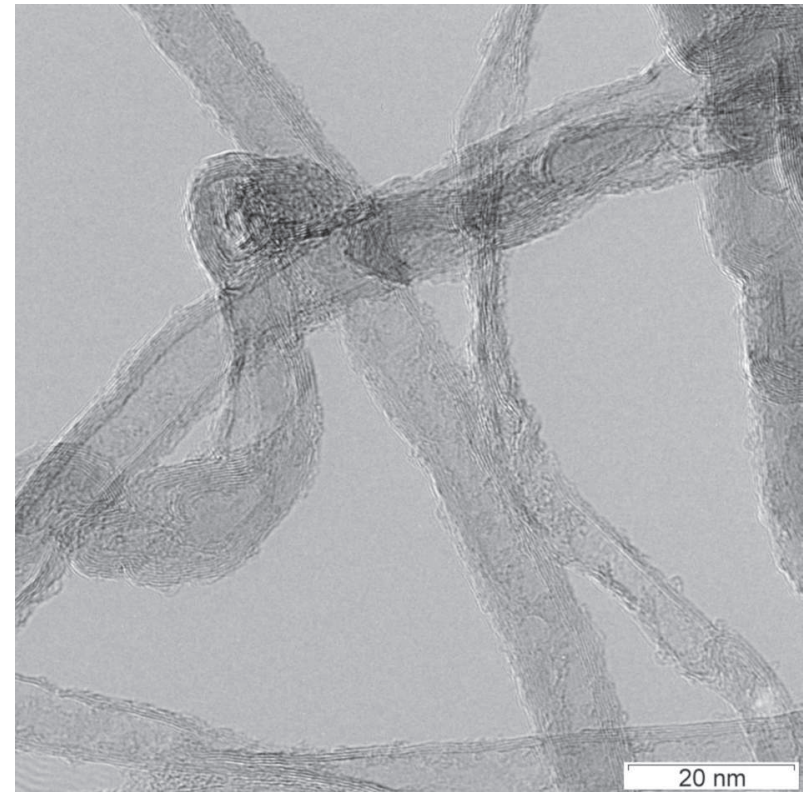

Figure 8. HRTEM micrograph of the MWCNT-PE adduct

ure 8 shows that the multiwalled CNT skeleton remained intact after the treatment with PE oligomers. The average number of CNT layers was calculated equal to 10 , a value close to the one estimated from the XRD pattern. The coherence between the results obtained from XRD and HRTEM indicates that the MWCNT-PE adduct shown in Figure 8 (CNT with 10 walls) is representative of the whole sample. CNT external surface resulted decorated with PE chains, which form a not continuous condensed polymer layer (from about 3 to about $9 \mathrm{~nm}$ thick) that appears tightly adhered to the CNT external surface.

The suspension of MWCNT-PE adduct was observed to be stable for at least 5 months. Figure 9 shows the pictures of the ethyl acetate suspensions of pristine MWCNT (Figure 9a) and MWCNT-PE after five months (Figure 9c).

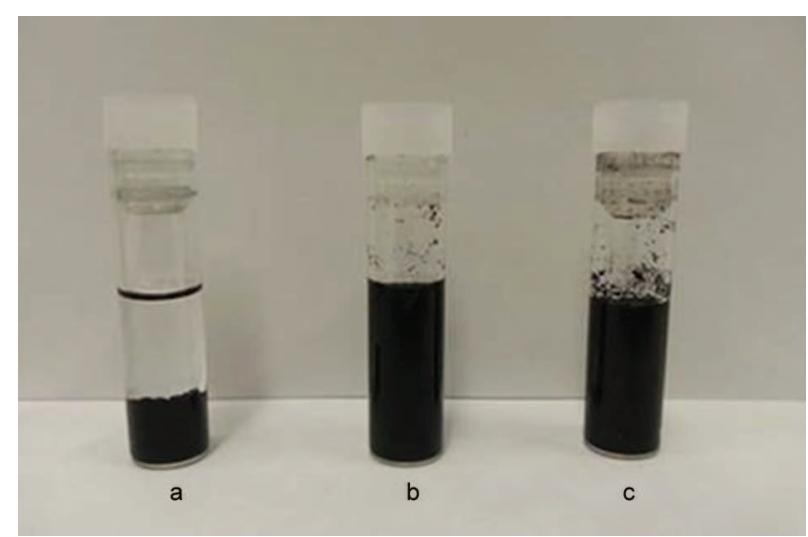

Figure 9. Ethyl acetate suspensions of $\operatorname{MWCNT}(a)$, MWCNT-PE (b) and MWCNT-PE adducts after 5 months storage (c) (PE from run 3 of Table 1)

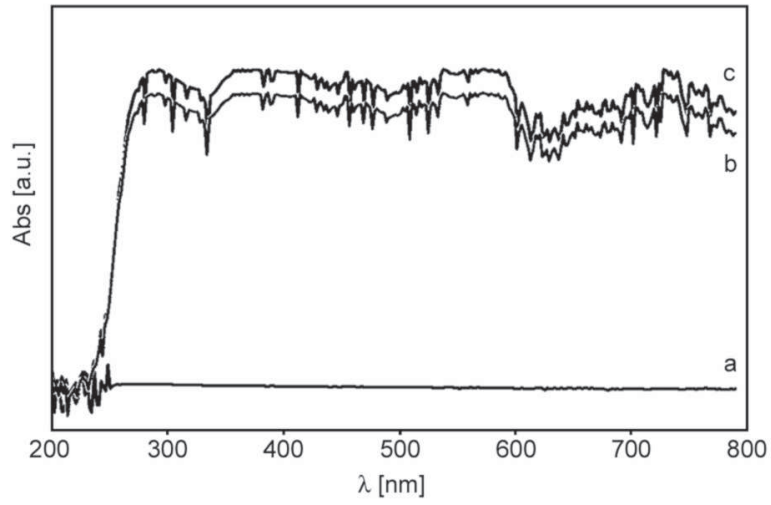

Figure 10. UV-Vis traces for ethyl acetate suspensions of: MWCNT (a), MWCNT-PE adduct (b), MWCNT$\mathrm{PE}$ adduct after five months storage (c) (PE from run 3 of Table 1)

UV-Vis absorption analysis was carried out on the suspensions shown in Figure 9, as described in the experimental part, by carefully taking the upper part of the supernatant suspensions. UV-Vis absorption spectra of such suspensions are reported in Figure 10. It is evident that the same absorbance was detected for the two suspensions, confirming that CNT treated with PE oligomer did not settle down, over five months storage.

As mentioned in the introduction, stable CNT dispersion in liquid media should be obtained through simple preparation processes, preserving CNT integrity. The approach here reported appears to achieve these goals. Thanks to SP based PE, a mild sonication is able to promote the formation of the stable suspension, without altering the CNT structure.

Stability of the interaction between SP based PE and MWCNT was investigated by solvent extraction. As mentioned in the Introduction, synergy was pursued between aromatic pyrrole rings and poly (oxyalkylene) sequences. Extraction tests with ethyl acetate were thus performed on MWCNT adducts with either SP based PE or with the PPG-PEG-PPG block copolymer. The former adduct was from run 3 of Table 1, the latter one was prepared as reported in the experimental part, with the Pluronic surfactant in place of SP based PE. TGA analysis of the ensuing products showed that absorbed SP based PE in the adduct was $13 \%$ before and 10\% after (Figure 11a). Instead, the pluronic surfactant was $5 \%$ before and $0.1 \%$ after extraction (Figure 11b). Mass loss is thus about 24 and $98 \%$ for the adduct with SP based PE and PPG-PEG-PPG respectively. These results are in line with the analysis of TEM micrographs (Figure 8) that reveal the intimate interaction of MWCNT with 

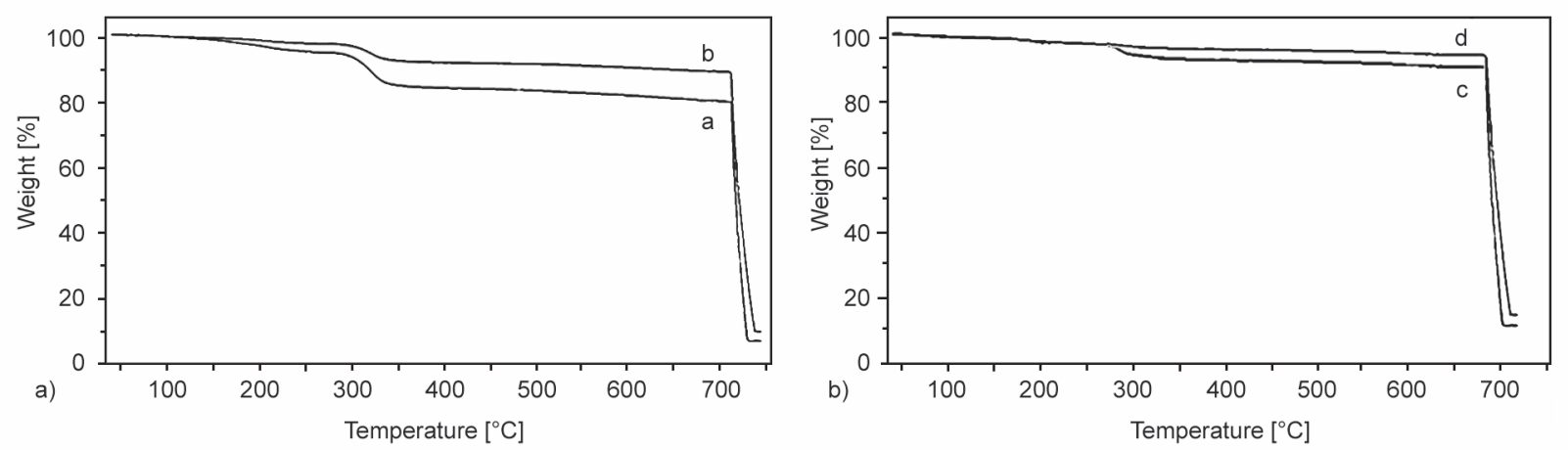

Figure 11. a) TGA curves taken under $\mathrm{N}_{2}$ of MWCNT-PE before (curve a) and after extraction process using ethyl acetate for 12 hours (curve b); (b). MWCNT-Pluronic before (curve c) and after extraction process using ethyl acetate as solvent for 12 hours (curve d)

the SP based PE and confirm the superior performance of surfactants containing poly(oxylakylene) sequences and an aromatic ring, inserted in the polymer chain by $\mathbf{S P}$.

\section{Conclusions}

Innovative, green, efficient synthetic strategy was designed and developed for the preparation of polyethers able to establish stable supramolecular interactions with carbon nanotubes. Serinol derivative containing a pyrrole ring, 2-(2,5-dimethyl- $1 H$-pyrrol-1yl)-1,3-propanediol (SP), was obtained from the reaction of serinol with 2,5-hexanedione and the subsequent aromatization of the tryciclic compound 4a,6a-dimethyl-hexahydro-1,4-dioxa-6b-azacyclopenta $[c d]$ pentalene. High yield solvent free reactions were performed by simply allowing the interaction of the starting reagents. PE oligomers were synthesized through the reaction of SP with DBI and their adduct with CNT was prepared by sonication in an environmentally friendly solvent such as acetone. Stability of the suspension was verified over months, even after centrifugation. HRTEM analysis revealed that CNT were prevailingly disentangled from the starting bundles, had intact skeleton and were decorated by PE oligomers, tightly adhered to the MWCNT external surface. Stability of the interaction of SP based PE with MWCNT was investigated by solvent extraction. With ethyl acetate at room temperature a very minor amount $(24 \%)$ of the SP based PE was extracted, whereas $98 \%$ of a PP-PE-PP block copolymer was removed in the same conditions.

This work demonstrates the synergy between the pyrrole rings and the oxyalkylene sequences for es- tablishing stable interaction with CNT, that can not be achieved by surfactants based only on poly(ethers). These results allow the preparation of even and stable CNT dispersions in a large variety of environments, from environmentally friendly (aqueous) liquids to polymeric matrices. SP is thus a versatile monomer for the preparation of polymeric surfactant for carbon allotropes.

\section{Acknowledgements}

'PRIN Research Project 2010-2011' is acknowledged for the financial support.

\section{References}

[1] Iijima S., Ichihashi T.: Single-shell carbon nanotubes of $1 \mathrm{~nm}$ diameter. Nature, 363, 603-605 (1993). DOI: $10.1038 / 363603 a 0$

[2] Bethune D. S., Kiang C. H., de Vries M. S., Gorman G., Savoy R., Vazquez J., Beyers R.: Cobalt-catalysed growth of carbon nanotubes with single-atomic-layer walls. Nature, 363, 605-607 (1993).

DOI: $10.1038 / 363605 \mathrm{a} 0$

[3] Iijima S.: Helical microtubules of graphitic carbon. Nature, 354, 56-58 (1991).

DOI: $\underline{10.1038 / 354056 \mathrm{a} 0}$

[4] Monthioux M., Kuznetsov V. L.: Who should be given the credit for the discovery of carbon nanotubes? Carbon, 44, 1621-1623 (2006).

DOI: $10.1016 /$ j.carbon.2006.03.019

[5] Dyke C. A., Tour J. M.: Covalent functionalization of single-walled carbon nanotubes for materials applications. The Journal of Physical Chemistry A, 108, 1115111159 (2004). DOI: $10.1021 / \mathrm{jp} 046274 \mathrm{~g}$

[6] Tasis D., Tagmatarchis N., Bianco A., Prato M.: Chemistry of carbon nanotubes. Chemical Reviews, 106, 1105-1136 (2006). DOI: $\underline{10.1021 / \mathrm{cr} 050569 \mathrm{o}}$ 
[7] Singh P., Campidelli S., Giordani S., Bonifazi D., Bianco A., Prato M.: Organic functionalisation and characterisation of single-walled carbon nanotubes. Chemical Society Reviews, 38, 2214-2230 (2009). DOI: 10.1039/B518111A

[8] Karousis N., Tagmatarchis N., Tasis D.: Current progress on the chemical modification of carbon nanotubes. Chemical Reviews, 110, 5366-5397 (2010).

DOI: $10.1021 / \mathrm{cr} 100018 \mathrm{~g}$

[9] Bergin S. D., Nicolosi V., Streich P. V., Giordani S., Sun Z., Windle A. H., Ryan P., Niraj N. P. P., Wang Z-T. T., Carpenter L., Blau W. J., Boland J. J., Hamilton J. P., Coleman J. N.: Towards solutions of singlewalled carbon nanotubes in common solvents. Advanced Materials, 20, 1876-1881 (2008).

DOI: $10.1002 / \mathrm{adma} .200702451$

[10] Jiménez P., Maser W. K., Castell P., Martínez M. T., Benito A. M.: Nanofibrilar polyaniline: Direct route to carbon nanotube water dispersions of high concentration. Macromolecular Rapid Communications, 30, 418-422 (2009).

DOI: $10.1002 /$ marc. 200800707

[11] Nakayama-Ratchford N., Bangsaruntip S., Sun X., Welsher K., Dai H.: Noncovalent functionalization of carbon nanotubes by fluorescein-polyethylene glycol: Supramolecular conjugates with $\mathrm{pH}$-dependent absorbance and fluorescence. Journal of the American Chemical Society, 129, 2448-2449 (2007).

DOI: $10.1021 / \mathrm{ja} 068684 \mathrm{j}$

[12] Belyanskaya L., Manser P., Spohn P., Bruinink A., Wick P.: The reliability and limits of the MTT reduction assay for carbon nanotubes-cell interaction. Carbon, 45, 2643-2648 (2007).

DOI: $10.1016 /$ j.carbon.2007.08.010

[13] Otsuka H., Nagasaki Y., Kataoka K.: Self-assembly of poly(ethylene glycol)-based block copolymers for biomedical applications. Current Opinion in Colloid and Interface Science, 6, 3-10 (2001).

DOI: $10.1016 /$ S1359-0294(00)00082-0

[14] Sardella E., Gristina R., Milella A., D’Agostino R., Favia P.: Functionalization of biomedical polymers by means of plasma processes: Plasma treated polymers with limited hydrophobic recovery and PE-CVD of $-\mathrm{COOH}$ functional coatings. Journal of Photopolymer Science and Technology, 15, 341-350 (2002). DOI: $10.2494 /$ photopolymer.15.341

[15] Holm B. A., Bergey E. J., De T., Rodman D. J., Kapoor R., Levy L., Friend C. S., Prasad P. N.: Nanotechnology in biomedical applications. Molecular Crystals and Liquid Crystals 374, 589-598 (2002). DOI: $10.1080 / 713738279$

[16] Schnabelrauch M., Vogt S., Larcher Y., Wilke I.: Biodegradable polymer networks based on oligolactide macromers: Synthesis, properties and biomedical applications. Biomolecular Engineering, 19, 295-298 (2002). DOI: $10.1016 / \mathrm{S} 1389-0344(02) 00034-5$
[17] Leobandung W., Ichikawa H., Fukumori Y., Peppas N. A.: Monodisperse nanoparticles of poly(ethylene glycol) macromers and N-isopropyl acrylamide for biomedical applications. Journal of Applied Polymer Science, 87, 1678-1684 (2003).

DOI: $10.1002 /$ app. 11612

[18] Thomas R. N., Guo C.: Surface-functionalized, probecontaining, polymeric nanospheres for biomedical imaging. Spectroscopy, 16, 387-398 (2002).

DOI: $10.1155 / 2002 / 818323$

[19] Vaisman L., Wagner H. D., Marom G.: The role of surfactants in dispersion of carbon nanotubes. Advances in Colloid and Interface Science, 128-130, 37-46 (2006).

DOI: 10.1016/j.cis.2006.11.007

[20] Rastogi R., Kaushal R., Tripathi S. K., Sharma A. L., Kaur I., Bharadwaj L. M.: Comparative study of carbon nanotube dispersion using surfactants. Journal of Colloid and Interface Science, 328, 421-428 (2008).

DOI: 10.1016/j.jcis.2008.09.015

[21] Pang J., Xu G., Tan Y., He F.: Water-dispersible carbon nanotubes from a mixture of an ethoxy-modified trisiloxane and pluronic block copolymer F127. Colloid and Polymer Science, 288, 1665-1675 (2010).

DOI: $10.1007 / \mathrm{s} 00396-010-2306-7$

[22] Blanch A. J., Lenehan C. E., Quinton J. S.: Optimizing surfactant concentrations for dispersion of singlewalled carbon nanotubes in aqueous solution. Journal of Physical Chemistry B, 114, 9805-9811 (2010). DOI: $10.1021 / j p 104113 \mathrm{~d}$

[23] Fernandes R. M. F., Abreu B., Claro B., Buzaglo M., Regev O., Furó I., Marques E. F.: Dispersing carbon nanotubes with ionic surfactants under controlled conditions: Comparisons and insight. Langmuir, 31, 10955-10965 (2015).

DOI: 10.1021/acs.langmuir.5b02050

[24] Andreeßen B., Steinbüchel A.: Serinol: Small molecule - big impact. AMB Express, 1, 1-6 (2011). DOI: $10.1186 / 2191-0855-1-12$

[25] Pagliaro M., Ciriminna R., Kimura H., Rossi M., Della Pina C.: From glycerol to value-added products. Angewandte Chemie International Edition, 46, 4434-4440 (2007).

DOI: 10.1002/anie.200604694

[26] Zhou C-H., Beltramini J. N., Fan Y-X., Lu G. Q.: Chemoselective catalytic conversion of glycerol as a biorenewable source to valuable commodity chemicals. Chemical Society Reviews, 37, 527-549 (2008). DOI: $\underline{10.1039 / \mathrm{B} 707343 \mathrm{G}}$

[27] Rahmat N., Abdullah A. Z., Mohamed A. R.: Recent progress on innovative and potential technologies for glycerol transformation into fuel additives: A critical review. Renewable and Sustainable Energy Reviews, 14, 987-1000 (2010). DOI: $\underline{10.1016 / \text { j.rser.2009.11.010 }}$ 
[28] Quispe C. A., Coronado C. J., Carvalho Jr J. A.: Glycerol: Production, consumption, prices, characterization and new trends in combustion. Renewable and Sustainable Energy Reviews, 27, 475-493 (2013).

DOI: $10.1016 /$ j.rser.2013.06.017

[29] Yang F., Hanna M. A., Sun R.: Value-added uses for crude glycerol - A byproduct of biodiesel production. Biotechnology for Biofuels, 5, 13/1-13/10 (2012). DOI: 10.1186/1754-6834-5-13

[30] Venkataraman S., Veronica N., Voo Z. X., Hedrick J. L., Yang Y. Y.: 2-Amino-1,3-propane diols: A versatile platform for the synthesis of aliphatic cyclic carbonate monomers. Polymer Chemistry, 4, 2945-2948 (2013). DOI: $10.1039 / \mathrm{C} 3 \mathrm{PY} 00318 \mathrm{C}$

[31] Cho H., Bae J., Garripelli V. K., Anderson J. M., Jun H-W., Jo S.: Redox-sensitive polymeric nanoparticles for drug delivery. Chemical Communications, 48, 6043-6045 (2012).

DOI: $10.1039 / \mathrm{C} 2 \mathrm{CC} 31463 \mathrm{~K}$

[32] Barbera V., Citterio A., Galimberti M. S., Leonardi G., Sebastiano R., Shisodia S. U., Valerio A. M.: Process for the synthesis of 2-(2,5-dimethyl-1h-pyrrol-1-yl)1,3-propanediol and its substituted derivatives. Word Patent WO/2015/189411 (2015).

[33] Galimberti M., Barbera V., Citterio A., Sebastiano R., Truscello A., Valerio A. M., Conzatti L., Mendichi R.: Supramolecular interactions of carbon nanotubes with biosourced polyurethanes from 2-(2,5-dimethyl-1Hpyrrol-1-yl)-1,3-propanediol. Polymer, 63, 62-70 (2015).

DOI: $10.1016 / \mathrm{j}$. polymer.2015.02.042

[34] Knorr L.: Einwirkung des diacetbernsteinsäureesters auf ammoniak und primäre aminbasen (in German). Berichte der deutschen chemischen Gesellschaft, 18, 299-311 (1885).

DOI: $10.1002 /$ cber. 18850180154

[35] Paal C.: Synthese von Thiophen- und Pyrrolderivaten (in German). Berichte der deutschen chemischen Gesellschaft, 18, 2251-2254 (1885). DOI: $10.1002 /$ cber. 18850180175

[36] Galimberti M., Barbera V., Guerra S., Conzatti L., Castiglioni C., Brambilla L., Serafini A.: Biobased Janus molecule for the facile preparation of water solutions of few layer graphene sheets. RSC Advances, 5, 81142-81152 (2015). DOI: $\underline{10.1039 / C 5 R A 11387 C}$
[37] Casagrande C., Fabre P., Raphaël E., Veyssié M.: 'Janus beads': Realization and behaviour at water/oil interfaces. Europhysics Letters, 9, 251-255 (1989). DOI: $10.1209 / 0295-5075 / 9 / 3 / 011$

[38] de Gennes P-G.: Soft matter (nobel lecture). Angewandte Chemie International Edition, 31, 842-845 (1992).

DOI: 10.1002 /anie.199208421

[39] Li F., Josephson D. P., Stein A.: Colloidal assembly: The road from particles to colloidal molecules and crystals. Angewandte Chemie International Edition, 50, 360-388 (2011). DOI: $10.1002 /$ anie.201001451

[40] Ropponen J., Nummelin S., Rissanen K.: Bisfunctionalized Janus molecules. Organic Letters, 6, 2495-2497 (2004). DOI: $10.1021 / 01049555 f$

[41] Saez I. M., Goodby J. W.: 'Janus' supermolecular liquid crystals-giant molecules with hemispherical architectures. Chemistry A European Journal, 9, 4869-4877 (2003). DOI: $10.1002 /$ chem. 200305100

[42] Ricciarelli R., Zingg J-M., Azzi A.: Vitamin E: protective role of a Janus molecule. The FASEB Journal, 15, 2314-2325 (2001).

DOI: 10.1096/fj.01-0258rev

[43] Mori H., Müller A. H.: New polymeric architectures with (meth)acrylic acid segments. Progress in Polymer Science, 28, 1403-1439 (2003). DOI: $\underline{10.1016 / \mathrm{S} 0079-6700(03) 00076-5}$

[44] Morrison R. T., Boyd R. N.: Organic chemistry, sixth edition. Prentice Hall, New York (1987).

[45] Gitsov I., Wooley K. L., Hawker C. J., Ivanova P. T., Frechet J. M.: Synthesis and properties of novel lineardendritic block copolymers. reactivity of dendritic macromolecules toward linear polymers. Macromolecules, 26, 5621-5627 (1993). DOI: $10.1021 / \mathrm{ma} 00073 \mathrm{a} 014$

[46] Mauro M., Cipolletti V., Galimberti M., Longo P., Guerra G.: Chemically reduced graphite oxide with improved shape anisotropy. The Journal of Physical Chemistry C, 116, 24809-24813 (2012).

DOI: $10.1021 / \mathrm{jp} 307112 \mathrm{k}$ 